\title{
Smile analysis in different facial patterns and its correlation with underlying hard tissues
}

\author{
Neha Grover ${ }^{1 *}$ (D, DN Kapoor ${ }^{2}$, Santosh Verma ${ }^{3}$ and Preeti Bharadwaj ${ }^{4}$
}

\begin{abstract}
Background: The subject's inherent growth pattern can be an effective factor in characteristics of smile. More vertical growth in the posterior maxilla than in the anterior maxilla could result in a changed relationship between the occlusal plane and the curvature of the lower lip upon smile. In order to broaden the understanding of how smile gets affected by growth pattern and the underlying hard tissues, the present study was undertaken to compare smile in various growth patterns, to determine sexual dimorphism, if any; as well as to correlate smile with underlying hard tissues.

Methods: One hundred and fifty subjects were selected amongst the students in the Dental Institute and from the outpatient department of Department Orthodontics and Dentofacial Orthopedics. Sample selected for the study ranged in the age group of 17 to 25 years. Selected individuals were subjected to lateral head cephalometric radiography in the Department of Oral Medicine and Radiology and videography. Cephalograms were traced and the subjects were divided into horizontal, average, and vertical growth pattern on the basis of GoGn-SN, lower anterior facial height, and Jaraback's ratio. The video clip was downloaded to obtain frame of posed smile. Cephalometric and photographic measurements were recorded and subjected to statistical analysis.

Results: The mean values of smile parameters were significantly higher in males as compared to females irrespective of the growth pattern. The mean incisal display, interlabial gap, lower lip to incisal edge distance, upper vertical lip length, and occlusal plane angle was highest in both males and females of vertical facial growth pattern group; whereas, the smile index, posterior corridor (left and right) were less in vertical facial growth pattern group in both males and females. Thus, the parameters in vertical dimension were increased in vertical growers whereas, the parameters in transverse dimension decreased.
\end{abstract}

Conclusions: The facial growth pattern has significant influence on the parameters of smile along with definite sexual dimorphism. The angular and linear parameters, except saddle angle and lower incisor to NB (linear and angular), influenced smile.

\section{Background}

The smile is one of the most important facial expressions and is essential in expressing friendliness, agreement, and appreciation. A smile when pleasing and attractive to observers enriches not only the one who smiles but also those who view it. An attractive or pleasing smile clearly enhances the acceptance of an individual in the society by improving the initial impression in interpersonal relationships [1]. The esthetic considerations are paramount in treatment planning; however,

\footnotetext{
* Correspondence: Ortho.neha@gmail.com

${ }^{1}$ Nora Medical Polyclinics, Tower 4. Marks and Spencer Building, No. 106, Abu Dhabi, United Arab Emirates

Full list of author information is available at the end of the article
}

rigid rules cannot be applied to this process because almost an infinite variety of faces could be esthetic [2].

There are two forms of smiles-the enjoyment or Duchenne smile and the posed or social smile. The posed smile is voluntary and not elicited by an emotion. In other words, it is reliably reproducible and can be sustained [3]. Posed smiles, therefore have importance in orthodontic diagnosis and treatment planning. The unposed or social smile, however, is involuntary and is induced by joy or mirth. It is a natural response as it expresses authentic human emotion. Unlike the posed smiles, these smiles are not sustained.

The vertical aspects of smile anatomy are the degree of maxillary anterior tooth display (Morley ratio), upper lip

\section{它 Springer}


drape, and gingival display. In a youthful smile, $75-100 \%$ of the maxillary central incisors should be positioned below an imaginary line drawn between the commissures [4]. Both skeletal and dental relationships contribute to these smile components. The present study was undertaken to compare smile in various growth patterns, to determine sexual dimorphism, if any; as well as to correlate smile with underlying hard tissues.

\section{Methods}

In this cross-sectional study, a total of 150 subjects were selected amongst the students studying in Dental College and the outpatient department of the College. Selected individuals ranged in age of 17-25 years had class I molar relation, well aligned anterior teeth, presence of all permanent teeth except third molars, no gross facial asymmetry, with no previous orthodontic treatment, and no history of facial trauma, plastic surgery, or orthognathic surgery.

Selected subjects were first taken for videography using Sony digital camera (DSC-H20, Sony Corp. Japan). Signed consent of the subjects was taken on using video for research purpose. The method used for videography here was as described by Sarver and Ackerman $[2,5,6]$. The subjects were instructed to hold their head in natural head position by looking straight into an imaginary mirror [7]. The camera lens was adjusted parallel to the apparent occlusal plane and focussed only on the dentofacial complex (corresponding to the area from the nose to the chin) (Fig. 1). Included in the captured area were two rulers with millimeter markings. These two rulers were made to fit perpendicular to each other in order to help minimize any error. If the subject was unable to hold the ruler perpendicular in one dimension to the angle in which the dynamic record was taken, the second ruler would still be perpendicular to the camera.

Recording was started about $1 \mathrm{~s}$ before the subject began to smile and continued till the end of the smile.

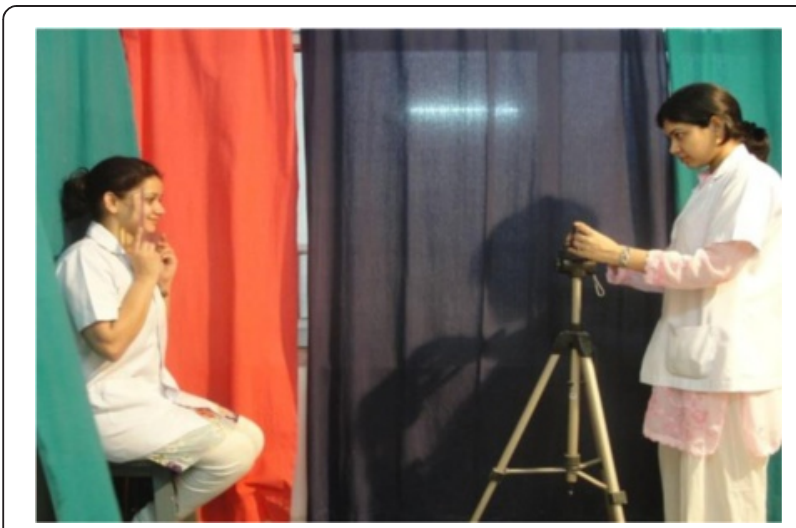

Fig. 1 Video camera set on a tripod at $4 \mathrm{ft}$ distance from the subject in sitting position
The video clip was downloaded to laptop (Dell, Inspiron) and uploaded to video-editing software program (DVD VideoSoft Studio) (Figs. 3 and 4) to obtain frames of smile. Each frame was analyzed and the frame showing the subjects' widest commissure to commissure was chosen as posed smile. These frames were converted into a JPEG file using the same video-editing software program (DVD VideoSoft Studio) (Fig. 2). The approval was taken from Institute Ethics Committee whose students were involved in the study.

The lateral head cephalogram of the selected subjects were taken with radiograph machine Villa (Italy, Strato 2000) using a standardized technique.

The cephalometric tracings were carried out, and the following cephalometric landmarks and planes were used in the study (Figs. 3 and 4). The parameters used to classify subjects in different groups are shown in Table 1.

Based on these three parameters, the subjects were divided into six groups:

A. Group 1: Males with average growth pattern

B. Group 2: Females with average growth pattern

C. Group 3: Males with horizontal growth pattern

D. Group 4: Females with horizontal growth pattern

E. Group 5: Males with vertical growth pattern

F. Group 6: Females with vertical growth pattern

\section{Standardization of image}

Each JPEG file of the selected subjects were opened in Adobe Photoshop CS2 (Adobe Systems, San Jose, California) and was adjusted by using the ruler option in the frame. The method used to standardize the image was as described by Desai et al [8]. First, the resolution was changed to 300 pixels per inch by going to "image > image size." Then, the ruler function was chosen and set to millimeter which can measure a minimum of $0.1 \mathrm{~mm}$ length. On the parallel end of the ruler, a $10-\mathrm{mm}$ area, close to the smile, was measured. That number was divided into 10 (10/measurement on JPEG file) and multiplied by the width value found in image size screen (image > image

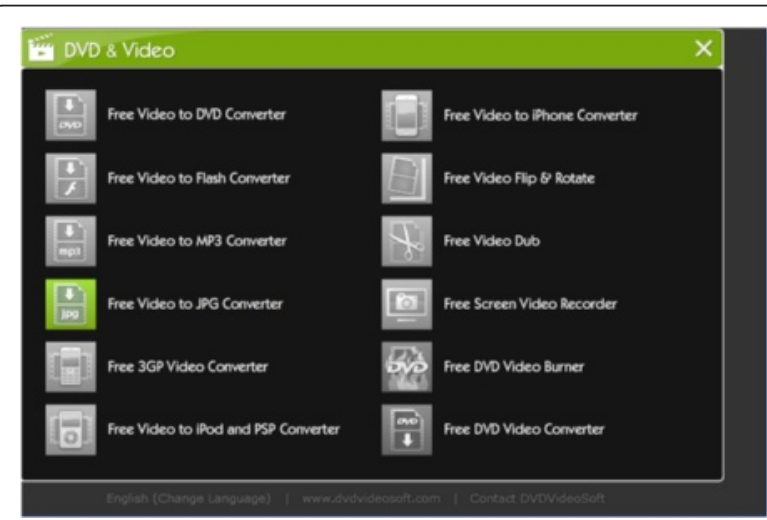

Fig. 2 Video to JPEG converter 


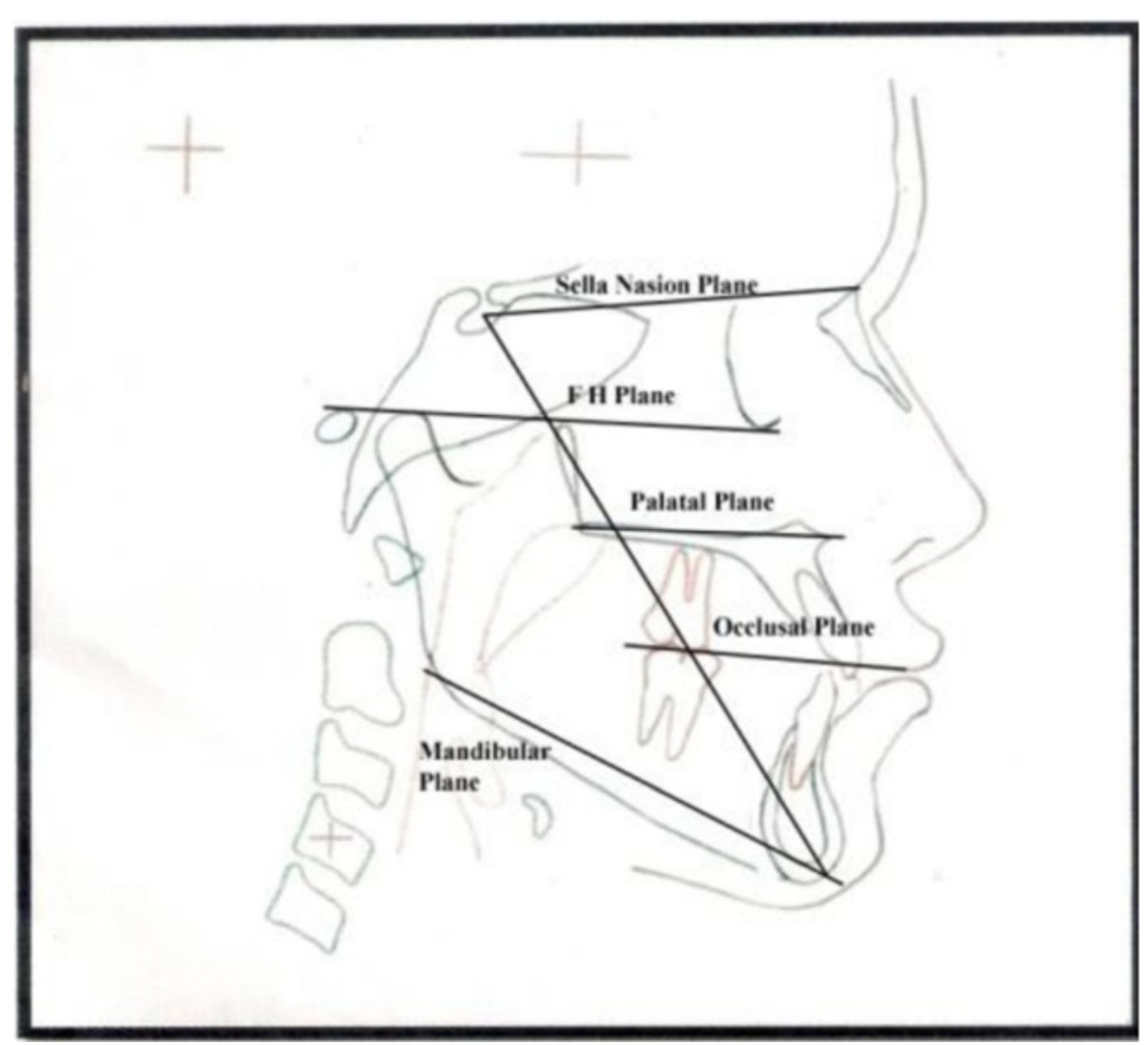

Fig. 3 Cephalometric planes

size). The resulting number was copied and pasted in place of the width reading, and the changes were applied to the JPEG file (Fig. 5).

In Adobe Photoshop, the following parameters of the selected subjects were measured and entered into Microsoft Excel to evaluate smile:

1. Maximum incisor exposure [9]: the amount of vertical display of the maxillary right central incisor (Fig. 6).

2. Lower lip to maxillary incisor [9]: vertical distance from the deepest midline point on the superior margin of the lower lip to the maxillary right central incisor edge (Fig. 7).

3. Interlabial gap [9]: the distance between the most inferior portion of the tubercle of the upper lip and the deepest midline point on the superior margin of the lower lip (Fig. 8).

4. Maxillary intercanine width [9]: the distance from the distal aspect of the right canine to the distal aspect of the left canine (Fig. 9).

5. Width of all visible maxillary teeth [9]: the distance from the distal aspect of the most posterior visible tooth on the right to the most posterior visible tooth on the left side of the maxilla (Fig. 10).
6. Smile width [9]: the distance from outer commissure to outer commissure on smile (Fig. 11).

7. Smile index [9]: smile width/interlabial gap (Fig. 12).

8. Right and left buccal corridors [9]: the horizontal distance from the distal aspect of the canine to the respective outer commissure (Fig. 13).

9. Right and left posterior corridors [9]: the horizontal distance from the distal aspect of the most posterior tooth visible on smile to the respective outer commissure (Fig. 14).

10. Buccal corridor ratio [9]: intercanine width/smile width (Fig. 15).

11. Posterior corridor ratio [9]: visible maxillary teeth width/smile width (Fig. 16).

12. Upper vertical lip thickness [9]: the vertical distance from the most superior peak of the lip to the most inferior portion of the tubercle of the upper lip (Fig. 17).

13. Lower vertical lip thickness [9]: the vertical distance from the deepest midline point on the superior margin of the lower lip to the most inferior portion of the lower lip (Fig. 18).

Double determination for assessment of inherent error in measurements was done on 20 random photographs 


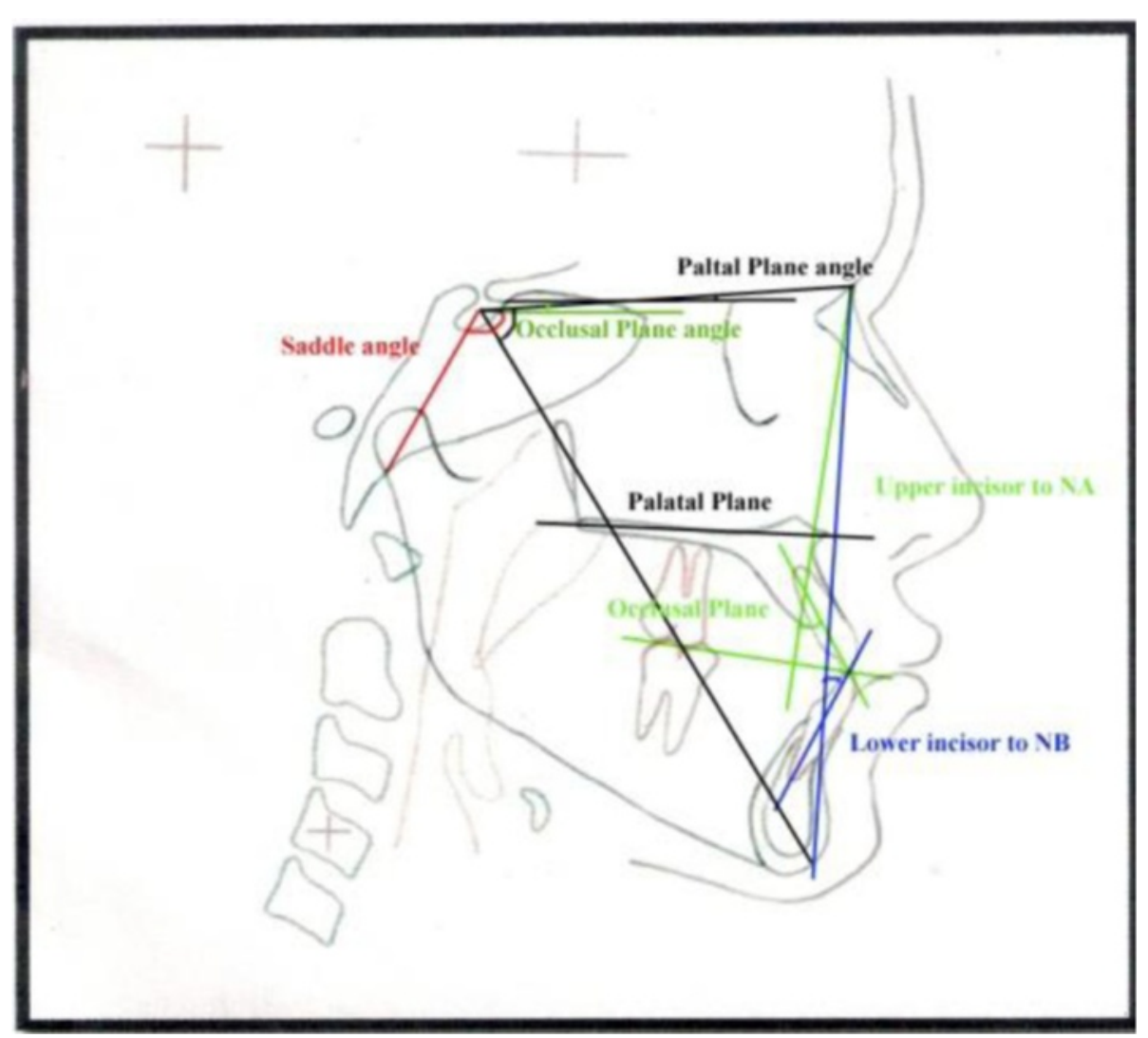

Fig. 4 Cephalometric parameters (angular and linear)

and cephalometric measurements. The variability was found to be statistically insignificant.

\section{Results}

The smile parameters of male and female were compared in all three growth patterns as shown in Tables 2 , 3 , and 4 .

As seen in Table 2, lower lip to maxillary incisor distance, interlabial gap, total width of visible teeth, posterior corridor ratio, and lower vertical lip thickness were significantly higher in males as compared to females in average growth pattern group.

According to Table 3, total width of visible teeth, smile width, buccal corridors left and right and lower vertical lip thickness were significantly higher in males as compared to females in horizontal growth pattern group.
Table 4 shows upper incisor exposure, interlabial gap, inter canine width, total width of visible teeth, posterior corridors left and right, and lower vertical lip thickness were significantly higher in males as compared to females in vertical growth pattern group.

Comparison of males in average group with horizontal growth pattern group and vertical growth pattern group was done separately as shown in Tables 5 and 6, respectively. Also comparison of females in average growth pattern group with horizontal growth pattern group and vertical growth pattern group was done separately as shown in Tables 7 and 8, respectively.

According to Table 5, upper incisor exposure and interlabial gap were significantly higher in males of average growth pattern group as compared to males of horizontal growth pattern group. Upper vertical lip thickness

Table 1 Parameters used for classification of growth pattern

\begin{tabular}{|c|c|c|c|c|c|}
\hline S. no. & Parameters & & Average & Vertical & Horizontal \\
\hline 1 & Jarabak's ratio (Jarabak [10]) & & $63.5 \pm 1.5 \%$ & $<62 \%$ & $>65 \%$ \\
\hline 2 & SN-GoGn (Steiner [10]) & & $32^{\circ} \pm 2^{\circ}$ & $>34^{\circ}$ & $<30^{\circ}$ \\
\hline \multirow[t]{2}{*}{3} & \multirow{2}{*}{$\begin{array}{l}\text { Lower anterior facial height } \\
\text { (McNamara [10]) }\end{array}$} & M & $72 \pm 2 \mathrm{~mm}$ & $>74 \mathrm{~mm}$ & $<70 \mathrm{~mm}$ \\
\hline & & $\mathrm{F}$ & $67 \pm 1 \mathrm{~mm}$ & $>68 \mathrm{~mm}$ & $<66 \mathrm{~mm}$ \\
\hline
\end{tabular}




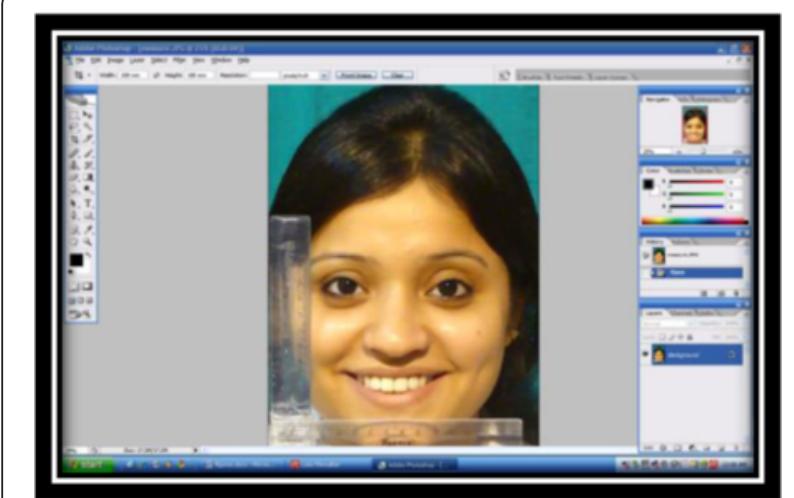

Fig. 5 Standardized photograph in Adobe Photoshop

was significantly higher in males of horizontal growth pattern group.

As seen in Table 6, upper incisor exposure, upper incisor to lower lip distance, interlabial gap, and upper vertical lip thickness were significantly higher in males of vertical growth pattern group as compared to males of average growth pattern group. Buccal corridors left and right and posterior corridors left and right were higher in average growth pattern group.

Table 7 shows upper incisor exposure and interlabial gap were significantly higher in females of average growth pattern group as compared to females of horizontal growth pattern group. Upper vertical lip thickness was significantly higher in females of horizontal growth pattern group.

As shown in Table 8, upper incisor exposure, upper incisor to lower lip distance, and interlabial gap were significantly higher in females of vertical growth pattern group as compared to females of average growth pattern group. Posterior corridors left and right were higher in average growth pattern group.

These results clearly show that the vertical parameters of smile were highest in vertical growth pattern group and least in horizontal growth pattern group in both males and females.

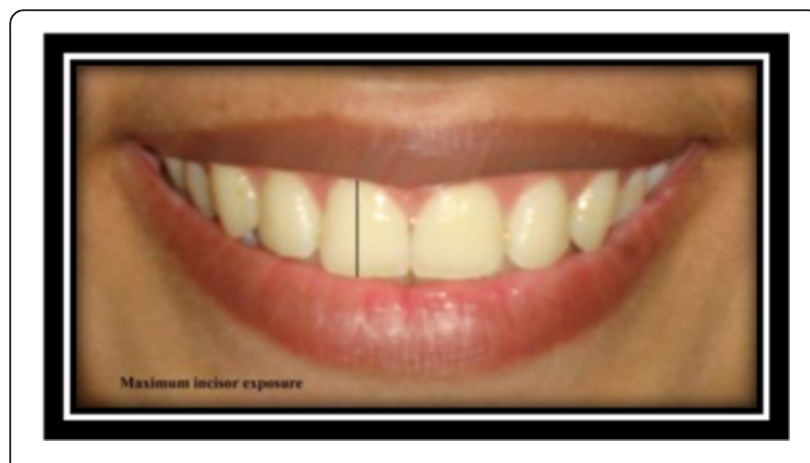

Fig. 6 Maximum incisor exposure

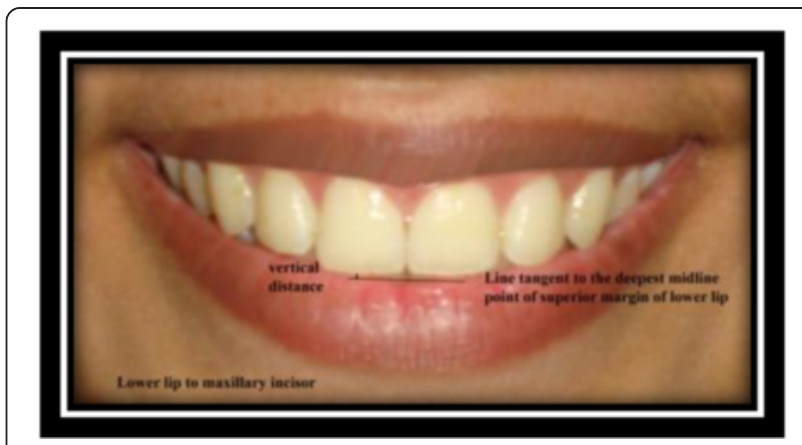

Fig. 7 Lower lip to maxillary incisor

Correlation between smile parameters and skeletal parameters of males in average facial growth pattern group, females in average facial growth pattern group, males in horizontal group, females in horizontal growth pattern group, males in vertical growth pattern group, and females in vertical growth pattern group is in Additional file 1.

Interlabial gap, when correlated with cephalometric parameters, was found to be positively correlated with overjet in average facial growth pattern group of males and was positively correlated with posterior facial height in average facial growth pattern group of females. The interlabial gap was positively correlated with lower anterior facial height in males having horizontal facial growth pattern and no correlations with other cephalometric measurements in females having horizontal facial growth pattern. In the vertical facial growth pattern group, interlabial gap was positively correlated with Yaxis and lower vertical lip length in males but insignificant correlations amongst females.

The incisal edge of the maxillary incisor to lower lip distance was found to be positively correlated with mandibular plane angle in average facial growth pattern group of males and was positively correlated with overjet in average facial growth pattern group of females. It was also positively correlated with palatal plane angle of females in horizontal facial growth pattern group.

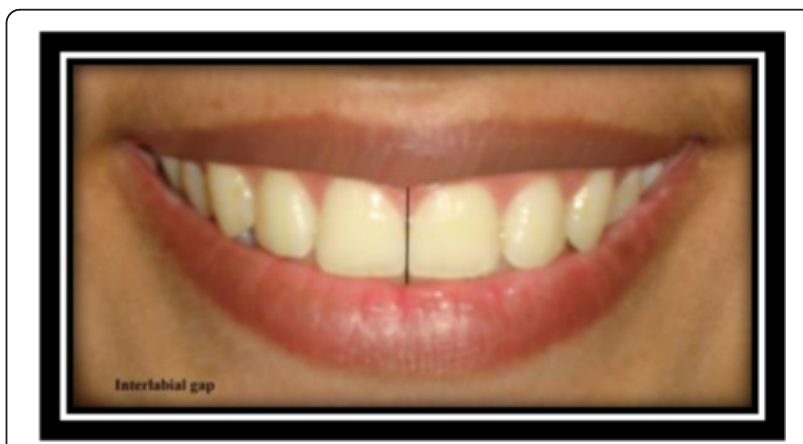

Fig. 8 Interlabial gap 


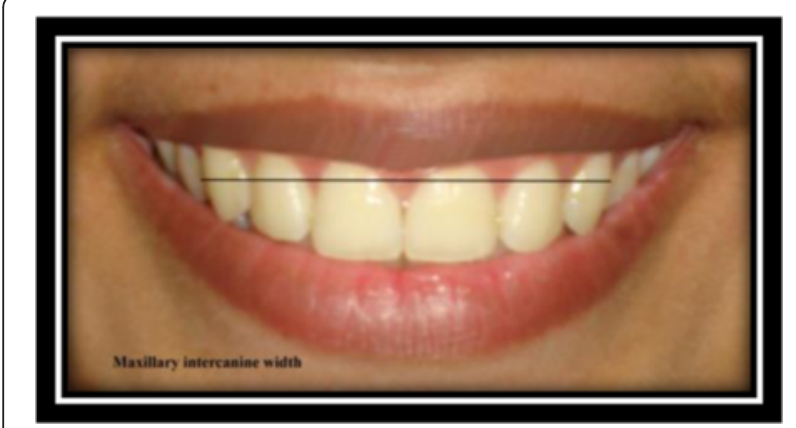

Fig. 9 Maxillary intercanine width

Based on these tables, it can be inferred that saddle angle and lower incisor to NB (angular and linear) was not found to be related to smile parameters and also upper incisor to NA (angular) was found to be positively correlated with upper lip vertical in females of all the three groups.

\section{Discussion}

To study a smile beyond static pictures, capturing a dynamic smile $[2,7,10]$ was used, thus avoiding the inherent error of a single snapshot. The variables of smile were significantly affected by the facial growth pattern in this study.

\section{Upper incisor exposure}

The upper incisor exposure was less in females when compared with males in all three groups and this difference was significant in vertical facial growth pattern group. This is contrary to the findings of Vig and Brundo [11], Peck et al. [12,13], and Balani et al [14], whereas the above finding is supported by a study done by Weeden et al. [15], where the results demonstrated that males exhibited greater amount of facial movements than females thus increasing the incisal display on smiling.

\section{Incisal display}

The incisal display significantly increased from horizontal to average to vertical facial growth pattern, with least

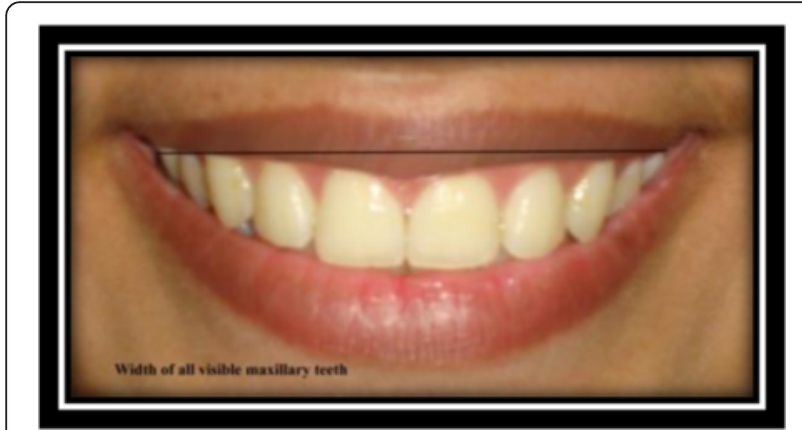

Fig. 10 Width of all visible maxillary teeth

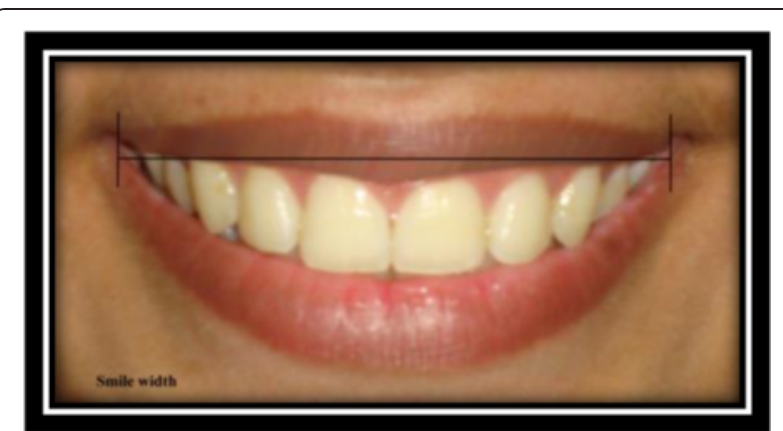

Fig. 11 Smile width

incisal display in horizontal facial growth pattern subjects and maximum in vertical facial growth pattern subjects for both males and females. Contrary to this, Mc Namara et al. [16] found that the vertical display on smile of the maxillary right central incisor could not be correlated with the skeletal vertical dimension, as measured from nasion to menton and from anterior nasal spine to menton.

On correlating upper incisor exposure with cephalometric parameters, it was found that the upper incisor display was negatively correlated with posterior facial height and Jaraback's ratio of males in horizontal facial growth pattern group but not in females and it was positively correlated with overjet, Y-axis, and palatal plane angle of males in vertical facial growth pattern group.

\section{Incisal edge to lower lip distance}

The incisal edge to lower lip distance was less in females when compared with males in all three groups and this difference was significant in average facial growth pattern group. This is supported by the findings of Vig and Brundo [11] and Peck et al. [12, 13] who found less mandibular tooth exposure in females than males at all ages.

The distance between incisal edge of the maxillary incisor and lower lip was least in horizontal growers and the maximum in vertical growers in both male and female.

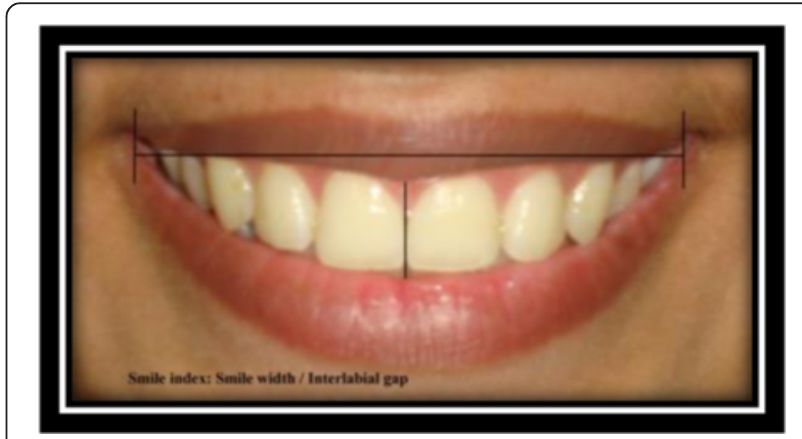

Fig. 12 Smile index 


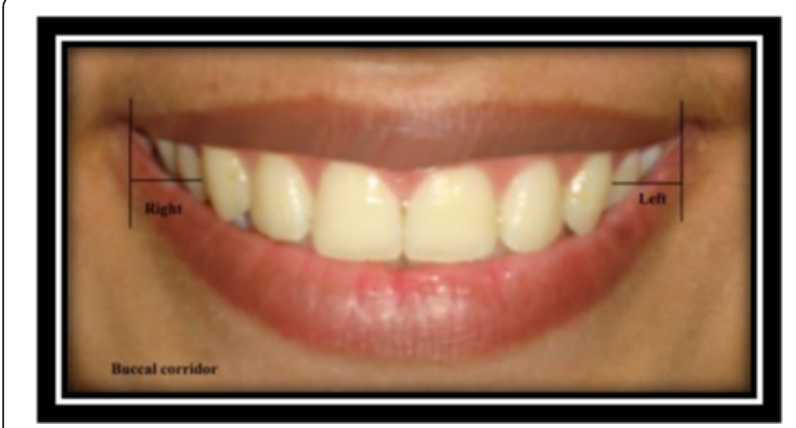

Fig. 13 Right and left buccal corridors

No correlations of distance between incisal edge of the maxillary incisor and lower lip were found with cephalomteric measurements in the vertical facial growth pattern group.

\section{Interlabial gap}

The interlabial gap was significantly more in males when compared to that in females in average and vertical facial growth pattern group. This was contrary to Rigsbee et al. [17], Tjan et al. [1], and Jensen et al [18] and is supported by a study done by Weeden et al. [15], where the results demonstrated that males exhibited greater amount of facial movements than females thus increasing the interlabial gap on smiling.

Interlabial gap was significantly found to be maximum in vertical growers, followed by average and least in horizontal growers in both male and female.

\section{Intercanine width}

The intercanine width was more in males when compared to that in females in all groups but this difference was statistically significant only in the vertical facial growth pattern group.

Intercanine width was positively correlated with total width of visible maxillary teeth on smile of males in average and vertical facial growth pattern groups but not of males in horizontal growth pattern group. In males and females of vertical growth pattern group, the intercanine

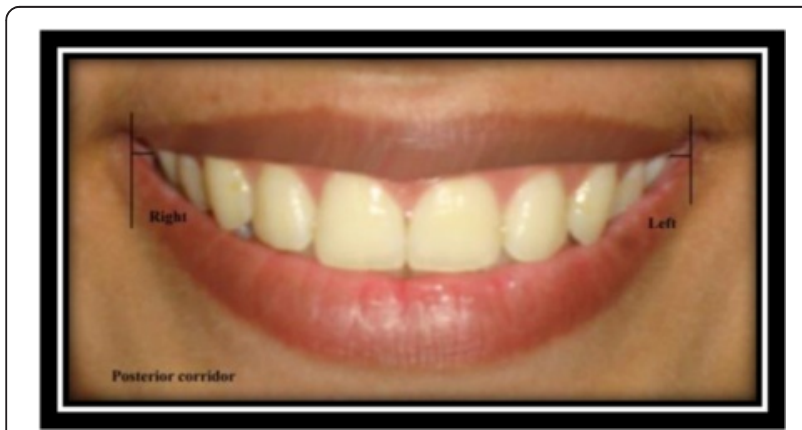

Fig. 14 Right and left posterior corridors

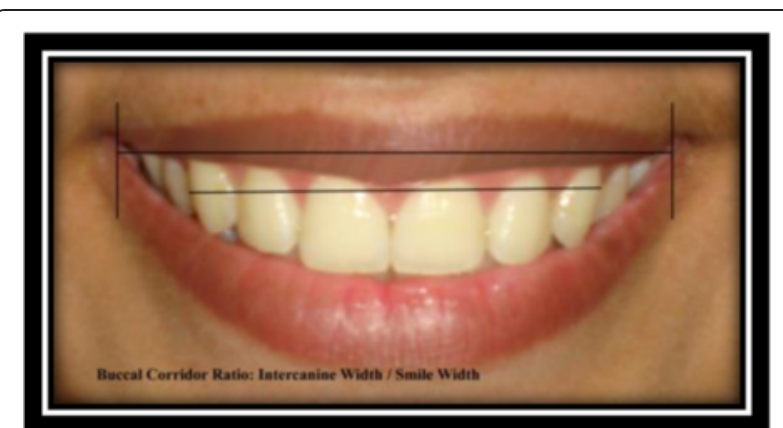

Fig. 15 Buccal corridor ratio

width was positively correlated with smile width and total width of visible maxillary teeth on smile.

The intercanine width was found to be least in vertical growers when compared with horizontal and average growers in both male a females. Similar results were found in a study done by Grippaudo et al. [19], in skeletal class II subjects. Changes in upper arch shape with intercanine diameter were proportionately smaller in patients with high angles and larger in low-angle patients.

\section{Total width of all visible maxillary teeth}

The total width of all visible maxillary teeth was significantly more in males when compared to that in females in all groups.

The total width of all visible maxillary teeth was negatively correlated with posterior corridor (left and right side) in all the groups indicating that in case of increased visible teeth during smile, the posterior corridor decreased. Due to the same reason, the total width of all visible maxillary teeth was negatively correlated with posterior corridor ratio in all the groups.

\section{Smile width}

The smile width was more in males when compared to that in females in all groups, but this difference was statistically significant only in the horizontal facial growth pattern group. This was contrary to the results of Rigsbee et al. [17] and Chetan et al. [20] who found that females

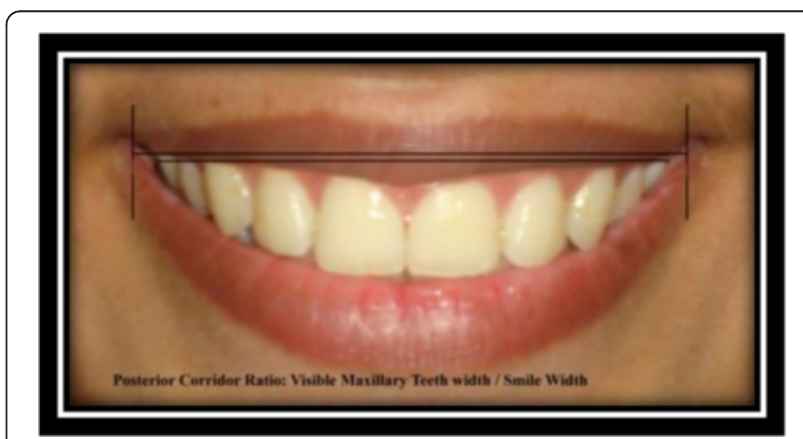

Fig. 16 Posterior corridor ratio 


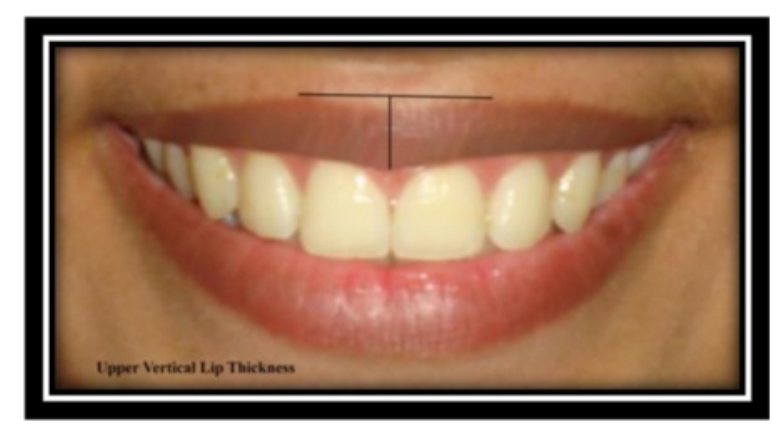

Fig. 17 Upper vertical lip thickness

exhibited more animation as compared to men resulting from a greater degree of upper lip elevation and increased width resulting in an increased display of teeth.

On comparing smile width separately in horizontal and vertical facial growth pattern group with average facial growth pattern group, statistically insignificant difference was found in both males and females in both the facial growth pattern groups.

\section{Buccal corridor}

With regard to the buccal corridor of males when compared with females, the mean value was found to be more in case of males in all groups but was significantly more only in males in horizontal facial growth pattern group. A similar finding was reported by Maulik and Nanda [21]who found that females had less buccal corridor space than males.

As regards buccal corridor of the left side when compared with the right side, statistically significant difference was found which demonstrates that the buccal corridor was greater on the left side than on the right side. This finding is supported by the study done by Okamoto et al. [22] where it was found that the displacements of the right and left corners of the mouth during voluntary smile were asymmetric and the leftsided laterality was found.

Buccal corridor of the left side when compared with the right side, in vertical facial growth pattern group

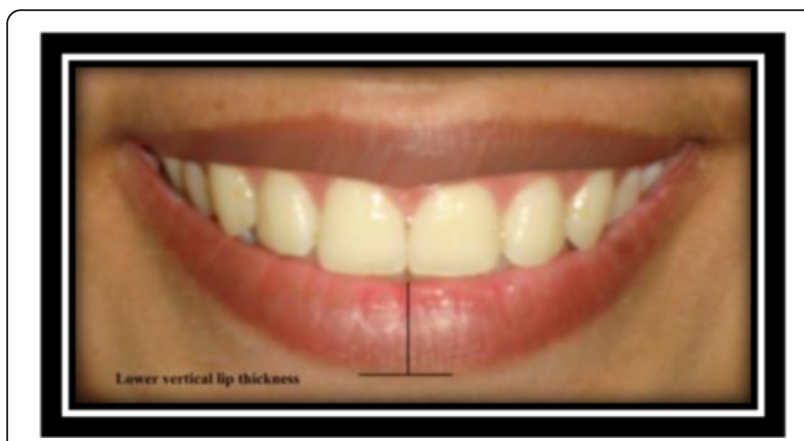

Fig. 18 Lower vertical lip thickness with average facial growth pattern group, was found to be significantly less in vertical facial growth pattern group in males but not in females. The above findings are supported by the results of Yang et al. [23] who found that FMA and LAFH were negatively correlated with buccal corridor.

The buccal corridors (left and right) were positively correlated to each other indicating that if the buccal corridor was increased on the left side, it would increase on the right side as well, in all the groups irrespective of the age. A similar finding was observed by Krishnan et al. [6] showing a high correlation between the right and left buccal corridor spaces in both men and women. It was also positively correlated with posterior corridor (left and right) indicating that in case of increased buccal corridor, the posterior corridor also increased. No correlation was found between the total anterior facial height and the buccal corridor space similar to the findings of Yang et al [23].

\section{Posterior corridor}

Posterior corridor of males, when compared with females, was found to be less in case of males in horizontal and average facial growth pattern groups but was statistically significantly less in males in vertical facial growth pattern group. On comparing posterior corridor of the left and right sides, statistically significant difference was found which indicate that the posterior corridor was greater on the left side than on the right side. This finding is supported by the study done by Okamoto et al. [22] where it was found that the displacements of the right and left corners of the mouth during voluntary smile were asymmetric, and the left-sided laterality was found.

Posterior corridor in vertical facial growth pattern group, when compared with average facial growth pattern group, was found to be significantly less in vertical facial growth pattern group in both males and females. On comparing buccal corridor of left and right sides in horizontal facial growth pattern group with average facial growth pattern group, it was found to be insignificantly different in both males and females.

The posterior corridors (left and right) were positively correlated to each other indicating that if the posterior corridor was increased on the left side, it would increase on the right side as well, in all the groups irrespective of the age.

\section{Upper lip vertical}

Upper lip vertical length in males and females demonstrated an insignificant difference in all the groups.

Upper lip vertical length of horizontal facial growth pattern group, when compared with average facial growth pattern group, indicated that upper lip vertical length was 
Table 2 Comparison of male and female in average growth pattern (comparison of groups 1 and 2)

\begin{tabular}{|c|c|c|c|c|c|c|}
\hline \multirow[t]{2}{*}{ Parameter } & \multirow{2}{*}{$\begin{array}{l}\text { Males } \\
\text { Mean } \pm \text { SD }\end{array}$} & Females & \multirow[t]{2}{*}{ Difference } & \multirow[t]{2}{*}{$t$ value } & \multirow[t]{2}{*}{$p$ value } & \multirow[t]{2}{*}{ Significance } \\
\hline & & Mean \pm SD & & & & \\
\hline U1 EXP. & $8.65 \pm 1.04$ & $8.46 \pm .85$ & .192 & 0.717 & .477 & NS \\
\hline LL-U1 & $.80 \pm 0.97$ & $0.14 \pm 0.22$ & .66 & 3.308 & .002 & $S^{*}$ \\
\hline IL GAP & $9.71 \pm 1.64$ & $8.44 \pm 0.82$ & 1.276 & 3.473 & .001 & $S^{* *}$ \\
\hline IC WIDTH & $40.29 \pm 2.39$ & $39.34 \pm 1.95$ & .952 & 1.544 & .129 & NS \\
\hline TW & $53.43 \pm 3.88$ & $49.66 \pm 3.23$ & 3.768 & 3.736 & $<0.001$ & $S^{* * *}$ \\
\hline SW & $67.39 \pm 4.63$ & $65.76 \pm 3.42$ & 1.632 & 1.419 & .162 & NS \\
\hline SI & $7.16 \pm 1.50$ & $7.87 \pm 8.87$ & 7.056 & -2.02 & .049 & $S^{*}$ \\
\hline BC_L & $13.89 \pm 1.542$ & $13.21 \pm 1.97$ & .68 & 1.358 & .181 & NS \\
\hline BC_R & $13.66 \pm 2.29$ & $12.68 \pm 2.01$ & .98 & 1.610 & .114 & NS \\
\hline PC_L & $7.60 \pm 2.38$ & $7.99 \pm 2.24$ & -.392 & 0.60 & .552 & NS \\
\hline$P C \_R$ & $6.82 \pm 2.15$ & $7.42 \pm 1.95$ & -.596 & 1.03 & .310 & NS \\
\hline BC RATIO & $6.00 \pm 5.16$ & $5.99 \pm 4.11$ & 6.49 & 0.049 & .961 & NS \\
\hline PC RATIO & $7.95 \pm 6.71$ & $7.57 \pm 6.07$ & 3.832 & 2.116 & .040 & $S^{*}$ \\
\hline U VERT & $5.98 \pm 1.27$ & $5.97 \pm 1.49$ & 0.012 & 0.031 & .976 & NS \\
\hline L VERT & $11.20 \pm 1.03$ & $10.33 \pm 1.09$ & .864 & 2.884 & .006 & $S^{* *}$ \\
\hline
\end{tabular}

NS $p>0.05$ : insignificant

${ }^{*} p<0.05$, significant at $5 \%$ significance level; ${ }^{* *} p<0.01$, significant at $1 \%$ significance level; ${ }^{* * *} p<0.001$, highly significant

more in horizontal and vertical growth pattern group in both males and females and least in average growers.

\section{Lower lip vertical}

For lower lip vertical length in males when compared with females, statistically significant difference was found showing increased lower vertical lip length in males in all the three groups.
With regard to the lower lip vertical length in horizontal and vertical facial growth pattern group when compared with average facial growth pattern group, no significant difference was found between the two groups in both males and females. In a study done by Joshi et al. [24], the lip position in relation to various malocclusions was studied which showed a significant difference in the sagittal lip positions in different skeletal

Table 3 Comparison of male and female in horizontal growth pattern (comparison of groups 3 and 4)

\begin{tabular}{|c|c|c|c|c|c|c|}
\hline \multirow[t]{2}{*}{ Parameter } & \multirow{2}{*}{$\begin{array}{l}\text { Males }(n=25) \\
\text { Mean } \pm \text { SD }\end{array}$} & \multirow{2}{*}{$\begin{array}{l}\text { Females }(n=25) \\
\text { Mean } \pm \text { SD }\end{array}$} & \multirow[t]{2}{*}{ Difference } & \multirow[t]{2}{*}{$t$ value } & \multirow[t]{2}{*}{$p$ value } & \multirow[t]{2}{*}{ Significance } \\
\hline & & & & & & \\
\hline U1 EXP. & $6.93 \pm 1.01$ & $7.36 \pm 1.14$ & 0.4360 & 1.43 & .160 & NS \\
\hline LL-U1 & $0.3 \pm 0.62$ & $0.15 \pm 0.29$ & 0.148 & 1.081 & .285 & NS \\
\hline IL GAP & $7.34 \pm 1.20$ & $7.4 \pm 1.24$ & 0.0560 & 0.162 & .872 & NS \\
\hline IC WIDTH & $40.14 \pm 1.84$ & $39.58 \pm 1.58$ & 0.5560 & 1.145 & .258 & NS \\
\hline TW & $52.92 \pm 2.83$ & $48.84 \pm 3.23$ & 4.0720 & 4.742 & $<0.001$ & $S^{* * *}$ \\
\hline SW & $68.02 \pm 3.59$ & $64.32 \pm 4.08$ & 3.708 & 3.410 & .001 & $S^{* *}$ \\
\hline $\mathrm{SI}$ & $9.47 \pm 1.38$ & $8.93 \pm 1.63$ & 5.34 & 1.249 & 0.22 & NS \\
\hline BC_L & $14.1 \pm 1.72$ & $12.82 \pm 2.30$ & 1.2760 & 2.219 & .032 & $S^{*}$ \\
\hline$B C \_R$ & $13.44 \pm 2.18$ & $11.86 \pm 1.85$ & 1.5840 & 2.768 & .008 & $S^{*}$ \\
\hline PC_L & $7.49 \pm 1.55$ & $7.69 \pm 1.77$ & 0.2000 & 0.425 & .672 & NS \\
\hline$P C \_R$ & $7.18 \pm 1.54$ & $6.93 \pm 1.45$ & .2440 & 0.576 & .567 & NS \\
\hline BC RATIO & $5.91 \pm 3.2$ & $6.17 \pm 3.85$ & 2.62 & -2.62 & 0.012 & $S^{*}$ \\
\hline PC RATIO & $7.78 \pm 3.36$ & $7.61 \pm 5.09$ & 1.76 & 1.45 & .155 & NS \\
\hline U VERT & $6.92 \pm 1.61$ & $6.87 \pm 1.61$ & .0520 & 0.114 & .910 & NS \\
\hline L VERT & $11.72 \pm 1.63$ & $10.42 \pm 1.23$ & 1.3000 & 3.18 & .003 & $S^{* *}$ \\
\hline
\end{tabular}


Table 4 Comparison of male and female in vertical growth pattern (comparison of groups 5 and 6)

\begin{tabular}{|c|c|c|c|c|c|c|}
\hline \multirow[t]{2}{*}{ Parameter } & \multirow{2}{*}{$\begin{array}{l}\text { Males } \\
\text { Mean } \pm \text { SD }\end{array}$} & \multirow{2}{*}{$\begin{array}{l}\text { Females } \\
\text { Mean } \pm \text { SD }\end{array}$} & \multirow[t]{2}{*}{ Difference } & \multirow[t]{2}{*}{$t$ value } & \multirow[t]{2}{*}{$p$ value } & \multirow[t]{2}{*}{ Significance } \\
\hline & & & & & & \\
\hline U1 EXP. & $10.42 \pm 1.28$ & $9.54 \pm .93$ & 0.88 & 2.78 & .008 & $S^{* *}$ \\
\hline LL-U1 & $1.82 \pm 2.02$ & $1.23 \pm 1.25$ & 0.59 & 1.25 & .219 & NS \\
\hline IL GAP & $12.95 \pm 2.79$ & $11.25 \pm 2.03$ & 1.70 & 2.46 & .017 & $S^{*}$ \\
\hline IC WIDTH & $39.81 \pm 1.85$ & $38.52 \pm 2.32$ & 1.29 & 2.17 & .035 & $S^{*}$ \\
\hline TW & $54.53 \pm 4.22$ & $50.55 \pm 3.87$ & 3.98 & 3.47 & .001 & $S^{* *}$ \\
\hline SW & $65.31 \pm 5.24$ & $64.94 \pm 5.58$ & 3.72 & .24 & .809 & NS \\
\hline SI & $5.49 \pm 1.98$ & $5.91 \pm 9.19$ & 4.16 & 0.96 & 0.344 & NS \\
\hline$B C \_L$ & $12.72 \pm 2.39$ & $13.04 \pm 2.28$ & 0.320 & -.49 & .63 & NS \\
\hline$B C \_R$ & $12.39 \pm 2.17$ & $12.39 \pm 2.23$ & 0.000 & .00 & 1.00 & NS \\
\hline PC_L & $5.51 \pm 1.63$ & $6.44 \pm 1.22$ & 0.924 & -2.27 & .028 & $S^{*}$ \\
\hline PC_R & $5.19 \pm 1.70$ & $6.24 \pm 1.42$ & 1.05 & -2.37 & .022 & $S^{*}$ \\
\hline BC RATIO & $7.75 \pm 8.19$ & $5.96 \pm 3.9$ & 1.798 & 1.09 & .278 & NS \\
\hline PC RATIO & $1.25 \pm 2.05$ & $7.80 \pm 4.38$ & 4.678 & 1.14 & .260 & NS \\
\hline U VERT & $6.81 \pm 1.47$ & $6.32 \pm 1.34$ & 0.488 & 1.23 & .226 & NS \\
\hline L VERT & $11.23 \pm 1.59$ & $9.89 \pm 2.05$ & 1.34 & 2.59 & .013 & $S^{*}$ \\
\hline
\end{tabular}

NS $p>0.05$ : insignificant

${ }^{*} p<0.05$, significant at $5 \%$ significance level; ${ }^{* *} p<0.01$, significant at $1 \%$ significance level

malocclusions. Thus, it can be inferred vertical as well as the sagittal skeletal features influence the overall soft tissue drape.

To homogenize the sample, only class I subjects were selected. Increasing the sample size randomly followed by categorizing them based on Angle's classification and using regression model to compute additional variables could further improve the study. The use of a three-dimensional methodology [25] can be used for analyzing anthropometric characteristics of soft tissue of face.

\section{Conclusions}

From the analysis and obtained results, the following conclusions can be drawn:

Table 5 Comparison of males between average and horizontal facial growth pattern (comparison of groups 1 and 3 )

\begin{tabular}{|c|c|c|c|c|c|c|}
\hline Parameter & Average $(n=25)$ & Horizontal $(n=25)$ & Difference & $t$ value & $p$ value & Significance \\
\hline U1 EXP. & $8.65 \pm 1.04$ & $6.93 \pm 1.04$ & 1.72 & 5.933 & 0.000 & $\mathrm{~S}^{* * *}$ \\
\hline LL-U1 & $0.80 \pm 0.97$ & $0.30 \pm 0.62$ & 0.50 & 2.168 & 0.035 & $S^{*}$ \\
\hline IL GAP & $9.71 \pm 1.64$ & $7.34 \pm 1.20$ & 2.36 & 5.814 & 0.000 & $S^{* * *}$ \\
\hline IC WIDTH & $40.29 \pm 2.39$ & $40.14 \pm 1.85$ & 0.14 & 0.245 & 0.807 & NS \\
\hline TW & $53.43 \pm 3.88$ & $52.92 \pm 2.83$ & 0.50 & 0.529 & 0.599 & NS \\
\hline SW & $67.39 \pm 4.63$ & $68.02 \pm 3.59$ & 0.63 & 0.539 & 0.592 & NS \\
\hline SI & $7.16 \pm 1.50$ & $9.47 \pm 1.38$ & 2.30 & 5.646 & 0.000 & $S^{* * *}$ \\
\hline$B C \_L$ & $13.90 \pm 1.54$ & $14.10 \pm 1.72$ & 0.20 & 0.441 & 0.661 & NS \\
\hline$B C \_R$ & $13.66 \pm 2.29$ & $13.44 \pm 2.18$ & 0.21 & 0.342 & 0.734 & NS \\
\hline$P C \_L$ & $7.60 \pm 2.38$ & $7.50 \pm 1.55$ & 0.10 & 0.176 & 0.861 & NS \\
\hline PC_R & $6.82 \pm 2.15$ & $7.18 \pm 1.54$ & 0.35 & 0.672 & 0.505 & NS \\
\hline BC RATIO & $0.60 \pm 0.052$ & $0.59 \pm 0.032$ & 0.009 & 0.752 & 0.456 & NS \\
\hline PC RATIO & $0.795 \pm 0.067$ & $0.78 \pm 0.034$ & 0.016 & 1.108 & 0.274 & NS \\
\hline U VERT & $5.98 \pm 1.27$ & $6.92 \pm 1.61$ & 0.944 & 2.301 & 0.026 & $S^{*}$ \\
\hline L VERT & $11.20 \pm 1.03$ & $11.72 \pm 1.63$ & 0.52 & 1.367 & 0.178 & NS \\
\hline
\end{tabular}


Table 6 Comparison of males between average and vertical facial growth pattern (comparison of groups 1 and 5)

\begin{tabular}{|c|c|c|c|c|c|c|}
\hline Parameter & Average $(n=25)$ & Vertical $(n=25)$ & Difference & $t$ value & $p$ value & Significance \\
\hline U1 EXP. & $8.65 \pm 1.04$ & $10.42 \pm 1.28$ & 1.77 & 5.36 & 0.000 & $\mathrm{~S}^{* * *}$ \\
\hline LL-U1 & $0.80 \pm 0.97$ & $1.82 \pm 2.02$ & 1.02 & 2.28 & 0.027 & $S^{*}$ \\
\hline IL GAP & $9.71 \pm 1.64$ & $12.94 \pm 2.79$ & 3.24 & 4.99 & 0.000 & $S^{* * *}$ \\
\hline IC WIDTH & $40.29 \pm 2.39$ & $39.80 \pm 1.85$ & 0.48 & 0.79 & 0.431 & NS \\
\hline TW & $53.43 \pm 3.88$ & $54.52 \pm 4.21$ & 1.10 & 0.96 & 0.342 & NS \\
\hline SW & $67.39 \pm 4.63$ & $65.31 \pm 5.23$ & 2.08 & 1.49 & 0.143 & NS \\
\hline SI & $7.16 \pm 1.50$ & $5.49 \pm 1.97$ & 1.66 & 3.36 & 0.002 & $S^{* *}$ \\
\hline BC_L & $13.90 \pm 1.54$ & $12.72 \pm 2.38$ & 1.17 & 2.07 & 0.044 & $S^{*}$ \\
\hline BC_R & $13.66 \pm 2.29$ & $12.39 \pm 2.17$ & 1.26 & 2.01 & 0.049 & $S^{*}$ \\
\hline PC_L & $7.60 \pm 2.38$ & $5.51 \pm 1.62$ & 2.08 & 3.61 & 0.001 & $S^{* *}$ \\
\hline PC_R & $6.82 \pm 2.15$ & $5.18 \pm 1.70$ & 1.63 & 2.97 & 0.005 & $S^{* *}$ \\
\hline BC RATIO & $0.60 \pm 0.052$ & $0.77 \pm 0.81$ & 0.175 & 1.07 & 0.291 & NS \\
\hline PC RATIO & $0.795 \pm 0.067$ & $1.24 \pm 2.05$ & 0.452 & 1.10 & 0.276 & NS \\
\hline U VERT & $5.98 \pm 1.27$ & $6.81 \pm 1.47$ & 0.83 & 2.14 & 0.037 & $S^{*}$ \\
\hline L VERT & $11.20 \pm 1.03$ & $11.23 \pm 1.58$ & 0.036 & 0.95 & 0.925 & NS \\
\hline
\end{tabular}

NS $p>0.05$ : insignificant

${ }^{*} p<0.05$, significant at $5 \%$ significance level; ${ }^{* *} p<0.01$, significant at $1 \%$ significance level; ${ }^{* * *} p<0.001$, highly significant

1. Smile parameters in males and females were statistically significantly different, with higher mean values for upper incisor exposure, incisal edge to lower lip distance, interlabial gap, intercanine width, total width, smile width, and lower lip vertical length in males than in females.

2. For the horizontal facial growth pattern group when compared to average facial growth pattern group, statistically significant higher mean differences were observed in average growth pattern in upper incisor exposure, incisal edge to lower lip distance, interlabial gap, and upper vertical lip length, irrespective of the sex. The smile index was more and difference was statistically significant in horizontal facial growth pattern group, in both males and females.

3. Vertical facial growth pattern group exhibited statistically significant higher mean difference in

Table 7 Comparison of females between average and horizontal facial growth patterns (comparison of groups 2 and 4 )

\begin{tabular}{|c|c|c|c|c|c|c|}
\hline Parameter & Average $(n=25)$ & Horizontal $(n=25)$ & Difference & $t$ value & $p$ value & Significance \\
\hline U1 EXP. & $8.45 \pm 0.84$ & $7.36 \pm 1.14$ & 1.09 & 3.84 & 0.000 & $\mathrm{~S}^{* * *}$ \\
\hline LL-U1 & $0.14 \pm 0.22$ & $0.15 \pm 0.29$ & 0.012 & 0.16 & 0.870 & NS \\
\hline IL GAP & $8.43 \pm 0.82$ & $7.40 \pm 1.24$ & 1.04 & 3.47 & 0.001 & $S^{* *}$ \\
\hline IC WIDTH & $39.33 \pm 1.94$ & $39.58 \pm 1.57$ & 0.24 & 0.49 & 0.623 & NS \\
\hline TW & $49.66 \pm 3.22$ & $48.84 \pm 3.22$ & 0.81 & 0.89 & 0.378 & NS \\
\hline SW & $65.76 \pm 3.41$ & $64.32 \pm 4.08$ & 1.44 & 1.36 & 0.181 & NS \\
\hline SI & $7.86 \pm 0.88$ & $8.93 \pm 1.62$ & 1.07 & 2.88 & 0.006 & $S^{* *}$ \\
\hline$B C \_L$ & $13.21 \pm 1.97$ & $12.82 \pm 2.30$ & 0.39 & 6.46 & 0.521 & NS \\
\hline$B C \_R$ & $12.68 \pm 2.01$ & $11.86 \pm 1.85$ & 0.82 & 1.50 & 0.140 & NS \\
\hline$P C \_L$ & $7.98 \pm 2.24$ & $7.69 \pm 1.76$ & 0.29 & 0.51 & 0.611 & NS \\
\hline PC_R & 7.411 .96 & $6.93 \pm 1.45$ & 0.48 & 0.99 & 0.325 & NS \\
\hline BC RATIO & $0.59 \pm 0.04$ & $0.61 \pm 0.038$ & 0.017 & 1.57 & 0.122 & NS \\
\hline PC RATIO & $0.76 \pm 0.06$ & $0.76 \pm 0.050$ & 0.004 & 0.257 & 0.798 & NS \\
\hline U VERT & $5.96 \pm 1.50$ & $6.87 \pm 1.62$ & 0.90 & 2.05 & 0.046 & $S^{*}$ \\
\hline L VERT & $10.33 \pm 1.08$ & $10.42 \pm 1.22$ & 0.092 & 0.28 & 0.780 & NS \\
\hline
\end{tabular}


Table 8 Comparison of females having average and vertical facial growth pattern (comparison of groups 2 and 6)

\begin{tabular}{|c|c|c|c|c|c|c|}
\hline Parameter & Average $(n=25)$ & Vertical $(n=25)$ & Difference & $t$ value & $p$ value & Significance \\
\hline U1 EXP. & $8.45 \pm 0.84$ & $9.53 \pm 0.93$ & 1.08 & 4.28 & 0.000 & $S^{* * *}$ \\
\hline LL-U1 & $0.14 \pm 0.22$ & $1.23 \pm 1.24$ & 1.09 & 4.31 & 0.000 & $S^{* * *}$ \\
\hline IL GAP & $8.43 \pm 0.82$ & $11.24 \pm 2.02$ & 2.81 & 6.42 & 0.000 & $S^{* * *}$ \\
\hline IC WIDTH & $39.33 \pm 1.94$ & $38.52 \pm 2.32$ & 0.82 & 1.35 & 0.185 & NS \\
\hline TW & $49.66 \pm 3.22$ & $50.55 \pm 3.87$ & 0.89 & 0.88 & 0.381 & NS \\
\hline SW & $65.76 \pm 3.41$ & $64.94 \pm 5.58$ & 0.82 & 0.63 & 0.534 & NS \\
\hline SI & $7.86 \pm 0.88$ & $5.90 \pm 0.92$ & 1.96 & 7.66 & 0.000 & $S^{* * *}$ \\
\hline$B C \_L$ & $13.21 \pm 1.97$ & $13.04 \pm 2.27$ & 0.177 & 0.29 & 0.772 & NS \\
\hline BC_R & $12.68 \pm 2.01$ & $12.39 \pm 2.22$ & 0.288 & 0.48 & 0.634 & NS \\
\hline PC_L & $7.98 \pm 2.24$ & $6.43 \pm 1.21$ & 1.55 & 3.04 & 0.004 & $S^{* *}$ \\
\hline$P C_{-} R$ & 7.411 .96 & $6.23 \pm 1.41$ & 1.18 & 2.45 & 0.018 & $S^{*}$ \\
\hline BC RATIO & $0.59 \pm 0.04$ & $0.59 \pm 0.03$ & 0.004 & 0.36 & 0.723 & NS \\
\hline PC RATIO & $0.76 \pm 0.06$ & $0.78 \pm 0.04$ & 0.023 & 1.55 & 0.127 & NS \\
\hline U VERT & $5.96 \pm 1.50$ & $6.32 \pm 1.33$ & 0.356 & 0.89 & 0.380 & NS \\
\hline L VERT & $10.33 \pm 1.08$ & $9.88 \pm 2.04$ & 0.444 & 0.96 & 0.343 & NS \\
\hline
\end{tabular}

NS $p>0.05$ : insignificant

${ }^{*} p<0.05$, significant at $5 \%$ significance level; ${ }^{* *} p<0.01$, significant at $1 \%$ significance level; ${ }^{* * *} p<0.001$, highly significant

upper incisor exposure, incisal edge to lower lip distance, interlabial gap, upper vertical lip length, and occlusal plane angle, than average facial growth pattern group in both males and females; whereas, the smile index and posterior corridor (left and right) were statistically significantly less in vertical facial growth pattern group in both males and females.

4. Intercanine width exhibited positive correlation with total width of all visible teeth during smile in average facial growth pattern group of males and in vertical facial growth pattern group of both males and females.

5. Smile width was positively correlated with posterior corridor (left and right) and buccal corridor (left and right) in all the groups in both males and females.

6. Buccal corridor of the left side was positively correlated with buccal corridor of the right side and posterior corridor of both sides in all the groups in both males and females.

7. Posterior corridor of the left side was positively correlated with posterior corridor of the right side in all the groups in both males and females.

8. Posterior corridor ratio was positively correlated with buccal corridor ratio in all the groups in both males and females.

9. Saddle angle and lower incisor to NB (angular and linear) were not found to be related to smile.

10. Upper incisor to NA (angular) was found to be positively correlated with upper lip vertical in females of all the three groups.

\section{Additional file}

Additional file 1: Correlation between smile parameters and skeletal parameters of males and females in different groups. Correlation between smile parameters and skeletal parameters of males in average facial growth pattern group, females in average facial growth pattern group, males in horizontal group, females in horizontal growth pattern group, males in vertical growth pattern group, and females in vertical growth pattern group.

\section{Competing interests}

The authors declare that they have no competing interests.

\section{Authors' contributions}

NG carried out the entire study and concluded the results. DNK guided the entire approach of the study. SV \& PB participated in the sequence alignment and review of the study. All authors read and approved the final manuscript.

\section{Author details}

${ }^{1}$ Nora Medical Polyclinics, Tower 4. Marks and Spencer Building, No. 106, Abu Dhabi, United Arab Emirates. ${ }^{2}$ Department of Orthodontics, Kothiwal Dental College \& Former Dean of Dental Faculty, KGMU, Lucknow, UP, India. ${ }^{3}$ Department of Orthodontics, Kothiwal Dental College \& Research Centre, Moradabad, UP, India. ${ }^{4}$ Department of Orthodontics \& Dentofacial Orthopedics, KD Dental College \& Hospital, Mathura, UP, India.

Received: 19 April 2015 Accepted: 14 August 2015

Published online: 04 September 2015

\section{References}

1. Tjan AHL, Miller GD. Some esthetic factors in a smile. J Prosthet Dent. 1984;51:24-8.

2. Sarver DM, Ackerman MB. Dynamic smile visualization and quantification: part 1. Evolution of the concept and dynamic records for smile capture. Am J Orthod Dentofacial Orthop. 2003;124:4-12.

3. Sarver DM. The importance of incisor positioning in the esthetic smile: the smile arc. Am J Orthod Dentofal Orthop. 2001;120:98-111. 
4. Morley J, Eubank J. Macroesthetic elements of smile design. Am Dent Assoc. 2001;132:39-45.

5. Ackerman MB, Ackerman J. Smile analysis and design in the digital era. J Clin Orthod. 2002;36:221-36.

6. Sarver DM, Ackerman MB. Dynamic smile visualization and quantification: Part 2. Smile analysis and treatment strategies. Am J Orthod Dentofac Orthop. 2003;124:116-27.

7. Lundström A, Lundström F, Lebret LM, Moorrees C. Natural head position at natural head orientation: basic considerations in cephalometric analysis and research. Eur J Orthod. 1995;17:111-20.

8. Desai S, Upadhyay M, Nanda R. Dynamic smile analysis: changes with age. Am J Orthod Dentofac Orthop. 2009;136:310.e1-310.e10.

9. Krishnan V, Daniel ST, Lazar D, Asok A. Characterization of posed smile by using visual analog scale, smile arc, buccal corridor measures, and modified smile index. Am J Orthod Dentofac Orthop. 2008;133:515-23.

10. Alexander Jacobson: Radiographic Cephalometry; From Basics to Videoimaging. 1st ed. Quintessence Publishing Co, Inc. 1995: 60-62.

11. Vig RG, Brundo GC. The kinetics of anterior tooth display. J Prosthet Dent. 1978; $39: 502-4$

12. Peck S, Peck L, Kataja M. The gingival line. Angle Orthod. 1992;62(2):91-100

13. Peck S, Peck L, Kataja M. Vertical lineaments of lip position. Am J Orthod Dentofac Orthop. 1992;101:519-24.

14. Balani R, Jain U, Kallury A, Singh G. Evaluation of smile esthetics in central India. APOS Trends Orthod. 2014:4:162-8.

15. Weeden JC, Trotman CA, Faraway JJ. Three dimensional analysis of facial movement in normal adults: influence of sex and facial shape. Angle Orthod. 2001;71:132-40.

16. McNamara L, McNamara Jr JA, Ackerman MB, Baccetti T. Hard- and softtissue contributions to the esthetics of the posed smile in growing patients seeking orthodontic treatment. Am J Orthod Dentofac Orthop. 2008;133:491-9.

17. Rigsbee $\mathrm{OH}$, Sperry TP, BeGole EA. The influence of facial animation on smile characteristics. Int J Adult Orthod Orthognath Surg. 1988;3:233-9.

18. Jensen J, Joss A, Lang NP. The smile line of different Ethnic groups in relation to age and gender. Acta Med Dent Helv. 1999:2(14):38-46.

19. Grippaudo C, Oliva B, Greco AL, Sferra S, Deli R. Relationship between vertical facial patterns and dental arch form in class II malocclusion. Prog Orthod. 2013;14:43.

20. Chetan P, Tandon P, Singh GK, Nagar A, Prasad V, Chugh VK. Dynamics of a smile in different age groups. Angle Orthod. 2013;83(1):90-6.

21. Maulik C, Nanda R. Dynamic smile analysis in young adults. Am J Orthod Dentofac Orthop. 2007;132:307-15.

22. Okamoto H, Haraguchi S, Takada K. Laterality of asymmetry in movements of the corners of the mouth during voluntary smile. Angle Orthod. 2010;80(2):223-9

23. Yang $\mathrm{H}, \mathrm{Nahm} \mathrm{DS}$, Baek SH. Which hard and soft tissue factors relate with the amount of buccal corridor space during smiling? The Angle Orthod. 2007;78(1):5-11.

24. Joshi M, Wu LP, Maharjan S, Raj M. Sagittal lip positions in different skeletal malocclusions: a cephalometric analysis. Prog Orthod. 2015;16:8.

25. Deli R, Galantucci L, Liano A, Gioia E. Three-dimensional methodology for photogrammetric acquisition of the soft tissues of the face: a new clinicalinstrumental protocol. Prog Orthod. 2013;14:32.

\section{Submit your manuscript to a SpringerOpen ${ }^{\circ}$ journal and benefit from:}

- Convenient online submission

- Rigorous peer review

- Immediate publication on acceptance

- Open access: articles freely available online

- High visibility within the field

- Retaining the copyright to your article

Submit your next manuscript at $\gg$ springeropen.com 